\title{
RADIO REFRACTIVITY STUDY IN AKURE-OWO DIGITAL MICROWAVE LINK IN SOUTH WESTERN NIGERIA
}

\author{
P. 0. Otasowie ${ }^{1, *}$ and F. O. Edeko ${ }^{2}$ \\ 1,2 Dept. of Electrical and Electronic EnGineERIng, University of Benin, BEnin City, Edo State. NiGERIA \\ Email addresses: ${ }^{1}$ potasowie@yahoo.co.uk, ${ }^{2}$ frededeko@yahoo.co.co.uk
}

\begin{abstract}
This work is a study of radio refractivity in Akure-Owo Digital Microwave Link in South Western Nigeria. Meteorological data of air temperature, atmospheric pressure, relative humidity, and water vapour pressure were measured between January and December 2006 at the observatory centre of the Nigerian meteorological agency (NIMET) situated at Akure Airport. The meteorological data collected were computed to obtain the refractivity, refractivity gradient and earth radius factor. The results of the study show that the refractivity gradient was greater than zero and vary slightly throughout the months of the year 2006. The highest value of refractivity gradient was in April and lowest value in September, the effective earth radius factor was observed to be less than one which implies that there is sub-refraction in the link. Sub refraction is a situation in which the radio signal beam is refracted upwards in the link thereby resulting in microwave link loss.
\end{abstract}

Keywords: effective earth radius factor, refractivity, refractivity gradient microwave link, sub-refraction

\section{INTRODUCTION}

The troposphere is the lowest region of the atmosphere and it extends from the earth's surface to an altitude of about $10 \mathrm{~km}$ at the middle latitudes, $6 \mathrm{~km}$ at the poles and up to $18 \mathrm{~km}$ at the equator [1,2]. The basic parameters that describe the troposphere region are pressure, temperature and relative humidity. Variations in these conditions within the troposphere cause changes in the refractive index of air and large scale changes of refractive index with height cause radio waves to be refracted and the effect can be quite significant at all frequencies $[3,4]$.

Propagation of waves in a microwave link is through the troposphere which is the non-ionized lowest portion of the atmosphere [5]. The refractive index is defined as [5].

$$
n=\sqrt{\varepsilon_{r}}=\frac{c}{v}
$$

Where $\varepsilon_{\mathrm{r}}$ is the dielectric constant of the troposphere $\mathrm{C}$ is the speed of light and $\mathrm{V}$ is the phase velocity of the wave in the medium. The refractive index is always greater than unity but for a radio wave travelling in air, it is only a small fraction greater than unity. For example the average ground refractive index (n) is 1.000315 which is an inconvenient number and hence radio refractivity $\mathrm{N}$ is defined as [6].

$$
\mathrm{N}=(\mathrm{n}-1) \times 10^{6}
$$

Substituting the value for the ground refractive index $(\mathrm{n}=1.000315$ into equation (2) yields a value for $\mathrm{N}$ as 315 units. The radio refractivity for links below 100 GHZ is given as [6].

$$
N=77.6 \frac{P}{T}+3.733 \times 10^{5} \frac{e}{T^{2}}
$$

where $\mathrm{P}$ is the atmospheric pressure, $\mathrm{T}$ is the absolute temperature in degree Kelvin and e is the partial pressure due to water vapour in millibars.

The value of $\mathrm{N}$ varies with altitude since pressure; temperature and humidity normally decrease exponentially with height.

A radio link designer should not be so much interested in the absolute level of refractivity but in the change in the value over the microwave front. It is thus the gradient of refractivity that is of interest [6]. The refractivity gradient is thus defined as:

$$
G=\frac{\Delta N}{\Delta h}
$$

Refractivity gradients change with time leading to anomalous propagation conditions. There is a convenient artifice which is used to account for the problem of refraction when the path profile is plotted. This is called the effective earth radius factor " $k$ " [6]. 
The K-factor is related to the refractivity gradient as $[6,7]$.

$$
K=\frac{1}{\frac{1+a d n}{d h}}
$$

If the radio refractivity index " $\mathrm{N}$ " defined in equation (2) is rearranged, we get;

$$
\mathrm{N}=\mathrm{N} \times 10^{6}+1
$$

To obtain the gradient there is need to differentiate equation (6) with respect to height.

$$
\frac{d n}{d h}=10^{-6} \frac{d N}{d h}=10^{-6} G
$$

Substituting this ratio equation (5) yields

$$
K=\frac{1}{1+0.006371 G}
$$

Using eqn (8) some commonly referred values of $\mathrm{K}$ to $\mathrm{G}$ can be obtained as shown in Table 1:

Table 1: Comparison of $K$ - factor versus Gradient in the troposphere

\begin{tabular}{ccc}
\hline $\begin{array}{c}\text { Earth radius } \\
\text { factor }(\mathrm{K})\end{array}$ & $\begin{array}{c}\text { Radio refractivity } \\
\text { gradient }(\mathrm{G})\end{array}$ & $\begin{array}{c}\text { Atmospheric } \\
\text { Refraction }\end{array}$ \\
\hline 1 & 0 & $\begin{array}{c}\text { Standard } \\
\text { refraction }\end{array}$ \\
4 & & $\begin{array}{c}\text { Standard } \\
\text { refraction } \\
\text { Ducting }\end{array}$ \\
$\infty$ (infinity) & -39 units $/ \mathrm{km}$ & refraction \\
$<1$ & $>0$ & Sub-refraction \\
\hline
\end{tabular}

Hence when the gradient of refractivity $(G)=-39$ units $/ \mathrm{km}$ (or $\mathrm{K}=4 / 3$ ) it is called standard refraction, when the gradient becomes positive, it is known as sub-refraction and can cause diffraction loss. When the gradient becomes more negative than $G=100 \mathrm{~N}$ units $/ \mathrm{km}$ it is called super - refraction and results in multipath fading, when the gradient becomes more negative than $G=-157$ units $/ \mathrm{km}$, ducting conditions occur resulting in severe multipath, beam spreading and even blackout conditions $[8,9]$.

\section{METHODOLOGY}

The meteorological data used in this work such as air temperature, atmospheric pressure, relative humidity and water vapour pressure were obtained from the observatory centre of the Nigeria Meteorological Agency (NIMET) at Akure Airport which is situated on the Akure - Owo microwave link.

Akure lies on latitude $071509.30 \mathrm{~N}$ and longitude 0051142.60E and Owo lies on latitude 071220.00N and longitude $0053402.00 \mathrm{E}$. The path length of the link is $41.42 \mathrm{~km}$. The link was chosen because it has a meteorological station (Akure Airport) situated on the link where meteorological parameters can be measured.

At the NIMET observatory centre at Akure Airport, temperature was measured with a dry bulb thermometer, atmospheric pressure was measured with a kew pattern barometer. Vapour pressure was measured with the psychrometer (which is a combination of dry and wet bulb thermometers). The readings from the dry and wet bulb thermometer were computed to get the relative humidity in percent and water vapour in millibars. The meteorological readings were recorded over a twenty four hours period daily for four weeks in the months of January to December 2006. The weekly total for the months were divided by number of hours multiplied by total number of days in the month as illustrated in equation (9).

$$
\begin{aligned}
& \text { Average meteorological readings } \\
& =\frac{\sum \text { weekly total meteorological readings }}{\Sigma \text { total no of hours } \mathrm{x} \text { total no of days }}
\end{aligned}
$$

\section{RESULTS AND DISCUSSION}

The computed average monthly meteorological data in the link are shown in Table 2

Table 2: Average monthly meteorological date in Akure-Owo digital microwave link for year 2006

\begin{tabular}{lcccc}
\hline Month & $\begin{array}{c}\text { Temperatur } \\
\mathrm{e}^{0} \mathrm{C}\end{array}$ & $\begin{array}{c}\text { Relative } \\
\text { Humidity } \\
(\%)\end{array}$ & $\begin{array}{c}\text { Vapour } \\
\text { Pressure } \\
(\mathrm{mb})\end{array}$ & $\begin{array}{c}\text { Atmospheric } \\
\text { Pressure } \\
(\mathrm{mb})\end{array}$ \\
\hline January & 29.2 & 92.5 & 28.0 & 1004.5 \\
February & 29.6 & 82.6 & 32.1 & 1003.8 \\
March & 29.2 & 81.3 & 31.8 & 1005.3 \\
April & 29.0 & 88.2 & 32.5 & 1004.3 \\
May & 27.4 & 86.3 & 30.8 & 1005.5 \\
June & 27.1 & 86.6 & 30.4 & 1007.8 \\
July & 25.3 & 91.0 & 29.8 & 1007.6 \\
August & 25.6 & 90.0 & 28.6 & 1007.6 \\
September & 26.0 & 92.3 & 29.9 & 1006.4 \\
October & 27.2 & 89.8 & 29.7 & 1006.5 \\
November & 28.7 & 65.6 & 32.1 & 1005.5 \\
December & 28.4 & 57.0 & 30.8 & 1004.2 \\
\hline
\end{tabular}

\section{ANALYSIS OF RESULTS}

(i) Computation of refractivity gradient - The values obtained in Table 2 were computed using equation (3), (4) and (5) to get Table 3. The computations are illustrated as:

$$
N=77.6 \frac{P}{T}+3.733 \times 10^{5} \frac{e}{T^{2}}
$$

Where $\mathrm{P}$ is the atmospheric pressure in millibars, $\mathrm{T}$ is the air temperature in Kelvin and e is the water 
vapour pressure in millibars. If we substitute the values of $\mathrm{P}, \mathrm{T}$ and e from Table 2 we get $\mathrm{N}$.

$$
G=\frac{d N}{d h}
$$

If we substitute the value of $\mathrm{N}$ and $\mathrm{h}$ we get $\mathrm{G}$, the height (h) is taken as 90 meters from the link budget of Akure-Owo digital microwave link [10]. From:

$$
K=\frac{1}{1+0.006371 G}
$$

If we substitute the value of $\mathrm{G}$ we get $\mathrm{K}$. The results of computation are shown in Table 3.

Table 3: Refractivity, refractivity gradient and earth radius factor for Year 2006

\begin{tabular}{lccc}
\hline Month & Refractivity (N) & $\begin{array}{c}\text { Refractivity } \\
\text { Gradient (G) }\end{array}$ & $\begin{array}{c}\text { Earth Radius } \\
\text { Factor (K) }\end{array}$ \\
\hline January & 373 & 4.14 & 0.973 \\
February & 388 & 4.31 & 0.973 \\
March & 389 & 4.32 & 0.973 \\
April & 391 & 4.34 & 0.973 \\
May & 387 & 4.30 & 0.973 \\
June & 387 & 4.30 & 0.973 \\
July & 387 & 4.30 & 0.973 \\
August & 382 & 4.24 & 0.974 \\
September & 374 & 4.16 & 0.974 \\
October & 383 & 4.26 & 0.973 \\
November & 390 & 4.33 & 0.974 \\
December & 386 & 4.29 & 0.973 \\
\hline
\end{tabular}

Table 4: Table showing refractivity gradient versus months for Year 2006

\begin{tabular}{lc}
\hline \multicolumn{1}{c}{ Month } & Refractivity Gradient \\
\hline January & 4.14 \\
February & 4.31 \\
March & 4.32 \\
April & 4.34 \\
May & 4.30 \\
June & 4.30 \\
July & 4.30 \\
August & 4.24 \\
September & 4.16 \\
October & 4.26 \\
November & 4.33 \\
December & 4.29 \\
\hline
\end{tabular}

(ii) From Table 4, it can be deduced that refractivity gradient lies between 4.14 to 4.34 units and the effective earth radius factor is 0.973 and 0.974 throughout the year. Hence, it can be stated that the refractive gradient of the link is greater than zero and the earth radius factor is less than one. This condition is called sub-refraction. A subrefraction condition is a situation in which the radio beam travelling in the link is refracted upward and hence the portion of the wave front that is received at the distant end will travel close to the ground than usual. This situation leads to signal degradation (attenuation).
It can also be deduced from the Table 4., that refractivity gradient is highest in April and lowest in January leading to an attenuation of $-2.0 \mathrm{dbm}$ in April and -0.97 in January [3]. Thus, it is expected that signal reception on the Akure-Owo digital microwave link will degrade more in April and good reception is more likely in January.

\section{CONCLUSION}

In this study of radio refractivity in Akure-Owo digital microwave link, the result of the study allows us to conclude as follows:

(i) The effective earth radius factor was computed as 0.973 and 0.974 respectively. This enables one to conclude that there is sub refraction in the link.

(ii) The refractivity gradient vary, slightly throughout the months of the year, it has its lowest value in January and highest value in April in year 2006.

Finally, this study is intended to serve as a database for the prediction of microwave communication impairment in South Western Nigeria.

\section{REFERENCES}

[1.] Isaakidis, A.S and Xenos, D. (2004). "Ten years analysis of tropospheric refractivity variations". Annals of Geophysics Vol 47, pp 1-6.

[2] Lear, M.W. (1980). “Computing atmospheric scale height for refraction corrections" (NASA) mission planning and analysis division Lyndon B Johnson space center.

[3] Otasowie, P.O. (2008). "A study and analysis of microwave link degradation due to Atmospheric conditions" (A case study of Akure-Owo digital microwave link) Ph.D Thesis submitted to the University of Benin, Benin City, Nigeria.

[4] Otasowie, P.O. and Edeko, F.O. (2009). "An investigation of microwave link degradation due to Atmospheric conditions" (A case study of Akure-Owo digital microwave link) Advances in Materials and System Technologies Vol. 62-64 pp 159-165.

[5] Webster, A. R (1987). "Angle-of-arrival and tropospheric multipath propagation”, IEEE Transactions on Antenna and Propagation, Vol. 35, No. 1, pp. 94-99.

[6] Manning, T. (1999). "Microwave Radio Transmission Guide" British library cataloguing in the publication data. pp 89-115.

[7] Hall, M.P.M. (1979). "Effects of the Troposphere on Radio Communications" Peter Peregrines Ltd. Stevenge UK. pp 178-190.

[8] Bashir, S.O. (1989). "Three years statistics of Refractive Index Gradient and Effective Radius factor for the state of Bahrain: IEE Conference Publications 301 (ICAP 89) pp 220-223.

[9] Battan, L. J. (1973). "Radio observation of the atmosphere"Univ. of Chicago Press, Chicago.pp 76-78.

[10 Nigerian Telecommunication Limited (2004). "Book on Microwave Communication" Harris Corporation Microwave Communication Division 